\title{
PRINCIPALES ASPECTOS DE LA LEY DE COMUNIDADES AGRICOLAS
}

\author{
PONENCIA DEL ABOGADO ANTONIO RABUCO RAMIREZ, ASESOR \\ JURIDICO DE JUNDEP, EN EL SEMINARIO "LEY DE COMUNIDADES \\ AGRICOLAS", ORGANIZADO POR LA CORPORACION JUVENTUDES PARA EL \\ DESARROLLO Y LA PRODUCCION (JUNDEP) EN EL MES DE NOVIEMBRE DE \\ 1995 EN LA CIUDAD DE LA SERENA.
}

\author{
ANTONIO RABUCO RAMIREZ \\ Asesor jurídico, Corporación JUNDEP. \\ Serena, Noviembre, 1995.
}

\section{1.- INTRODUCCION}

Referirse a la norma reguladora de la constitución y funcionamiento de las Comunidades Agrícolas (CCAA), requiere realizar previamente la aclaración que la actual ley es una síntesis de cuatro normas diferentes, dictadas en momentos históricos diversos, a saber : El D.F.L. R.R.A. $n^{\circ} 19$ de 1963, el D.F.L. ${ }^{\circ} 5$ de 1967 , la ley 18.353 de 1984 y la ley 19.233 de 1993.

Estas al ser concebidas y promulgadas en momentos distintos, consagran una regulación que no resulta todo lo adecuada ni coherente que los destinatarios directos de la norma, los comuneros de la CCAA., quisieran.

El D.F.L. $n^{\circ} 5$, que modificó, complementó y fijó el texto refundido del D.F.L. $n^{\circ} 19$ de 1963, fue dictado en el período de la Reforma Agraria, y significó la consagración legal de una forma comunitaria para adquirir el dominio de la tierra, situación extraordinaria para el Derecho chileno, que como la mayoría de los ordenamientos jurídicos que responden a la tradición del Derecho continental, mira con incomodidad la institución de la comunidad en general.

Se debe hacer la salvedad, que en el caso de las CCAA, lo que el legislador realizó, fue reconocer la existencia de estas agrupaciones, que existían con una cierta organización común y con una base cultural previa al proceso de la Reforma Agraria. Esta puede ser una diferencia substancial con otras organizaciones que se generaron en ese período, como los asentamientos, las cooperativas campesinas o los sindicatos campesinos, que sí fueron obra del legislador, en su afán de generar en el mundo de la ruralidad, instancias de asociatividad que permitieran a los campesinos chilenos, integrarse al proceso de transformaciones estructurales que se impulsaban en Chile en la década del sesenta.

Las razones que pueden explicar el reconocimiento expreso de las CCAA a nivel de norma de rango legal, pueden ser reseñadas de la siguiente manera.

a) Existía una situación de hecho, configurada por un grupo humano que desarrollaba parte importante de su ciclo vital en terrenos sobre los que se ejercía una 
posesión común. Esta posesión se genera en mercedes de tierras otorgadas por la Corona española, concedidas normalmente en terrenos de secano, poco productivos y que respondían a una propiedad ancestral comunitaria, manifestada en la estructuración social de pequeños agricultores vinculados por lazos de parentezco o de amistad, en torno a una propiedad común de una extensión territorial indivisa.

Esta propiedad al transmitirse en forma comunitaria, se separa de la tendencia general de la propiedad raíz en Chile, que busca radicar individualmente en el patrimonio de cada uno de los herederos una propiedad distinta de la propiedad común.

b) Esta situación de hecho, no encerraba la potencialidad de estimular la reproducción de este tipo de propiedad, en lugares del territorio nacional en los que no existía esta experiencia histórica, ya que las CCAA durante largo tiempo han sido definidas como de economía campesina de subsistencia, caracterizadas por una situación de extrema pobreza.

c) La tercera razón de la consagración legislativa de este tipo de comunidad, se encuentra en la ya mencionada conyuntura favorable que encontraron los grupos rurales más empobrecidos, en la década del sesenta, para la búsqueda de alternativas organizacionales de tipo legal que permitieran morigerar sus niveles de pobreza.

EI D.F.L. $n^{\circ} 5$, permitió la constitución formal y funcionamiento de las CCAA, en un marco de relativa solidez de dichas instituciones dentro de las condiciones desmedradas en que, en general, las organizaciones campesinas debieron subsistir a partir de la instauración del Gobierno Militar y del impulso de una serie de políticas agrícolas, que estructuraron una virtual contrarreforma agraria.

Como expresión de esta política estatal, debilitadora de las organizaciones campesinas, se dicta el año 1984 , la ley 18.353 , que modifica el D.F.L. $n^{\circ} 5$, introduciendo reformas que apuntaban inyectar en el sistema de las CCAA, elementos que se contradecían con elementos fundamentales de estas organizaciones.

Dentro de estas modificaciones, la más importante fue la de otorgar a los comuneros, la posibilidad de acogerse al D.L. 2.695, que regula el saneamiento individual de la propiedad raiz, solicitando y obteniendo la inscripción de su Goce Singular individualmente. La aplicación de esta norma, que hasta esa fecha estaba expresamente vedada, implicaba generar las condiciones normativas que permitieran en la práctica, la liquidación de las CCAA, al salir de su patrimonio las tierras con una mayor capacidad productiva.

Terminado el Gobierno Militar e iniciado un proceso de apertura de espacios democratizadores de la vida nacional, las organizaciones a través de las cuales se aglutinan las CCAA (Federación Nacional y Asociaciones Provinciales), materializan un proceso de petición de reformas del D.F.L. $n^{\circ} 5$, introduciendo a dicho cuerpo legal, modificaciones que por un lado perfeccionaran aspectos que desde la dictación del D.F.L. $n^{\circ}$ 5, en 1964 se encontraban pendientes, y por otro, se revirtieran los efectos negativos que sobre la estabilidad de las CCAA, se produjeron con la dictación de la ley 18.353.

Uno de los aspectos fundamentales que se propone modificar, es la supervigilancia constante que sobre el funcionamiento de las CCAA ejercían organismos públicos. Este control se manifestaba desde la nulidad de los acuerdos de la Comunidad Agrícola tomados sin notificar al Ministerio de Bienes Nacionales acerca de la reunión en que dicho 
acuerdo se tomara, hasta la aprobación judicial de las reformas que la Comunidad quisiera introducir en sus estatutos. Esta situación consagraba tácitamente una especie de incapacidad relativa de los miembros de una Comunidad Agrícola. Al Legislador chileno, le parecía conveniente, a partir de esta concepción de incapacidad práctica de los comuneros, consagrar un nivel de intervención permanente del estado en la vida de las CCAA. La derogación de esta supervigilancia jerárquica fue uno de los objetivos mas importantes del proceso modificatorio de la normativa de las CCAA.

Como producto de lo anterior, y después de un debate en el que cupo un papel importante a las ya citadas organizaciones de CCAA, se publicó en el Diario Oficial de 5 de Agosto de 1993, la ley 19.233, la que sin acoger en su integridad la propuesta de las organizaciones de CCAA, introduce una serie de modificaciones al D.F.L. $n^{\circ} 5$, las principales de las cuales, ocupan un lugar preponderante de esta ponencia.

\section{2.- CONCEPTOS FUNDAMENTALES}

Una de las falencias importantes que exhibía el originario D.F.L. $n^{\circ} 5$, era por un lado, una definición de Comunidad Agrícola deficiente y no concordante con lo que efectivamente constituían las CCAA, y por otro, la inexistencia de definiciones que determinaran los límites conceptuales de instituciones fundamentales en el andamiaje jurídico de las CCAA, como son por ejemplo, Goce Singular, Lluvia, Terreno Común, Comunero.

Ante este panorama, la ley 19.233 consagra una nueva definición de Comunidad Agrícola y, además, entrega una serie de definiciones que establecen una positivación de instituciones que regían en el ámbito consuetudinario de las CCAA

\section{1.- Definición de Comunidad Agrícola.}

Antes de la modificación de la ley 19.233 , el art. $1^{\circ}$ del D.F.L. $n^{\circ} 5$ definía a las CCAA como "aquellos terrenos rurales pertenecientes a diversos propietarios en común, en los cuales el número de comuneros sea manifiestamente superior a la capacidad productiva del predio para que los respectivos grupos familiares puedan subvenir a sus necesidades esenciales de subsistencia".

Una de las deficiencias de dicha definición, radicaba en su carácter marginalista pues buscaba reconocer el derecho a la constitución de la propiedad agraria en forma comunitaria, sólo cuando de ella dependía la subsistencia de los respectivos grupos familiares. La primera dificultad surge al momento de determinar que es lo que se entiende cualitativa y cuantitativamente por subsistencia. Por otro lado, social y económicamente la definición no era exacta, puesto que los elementos conformadores de la Comunidad Agrícola, no corresponden total y exactamente a su baja capacidad productiva.

Otra de las críticas que se proyectaba desde los mismos comuneros, era la definición de la Comunidad Agrícola desde el terreno y no desde las personas. Quienes conforman la Comunidad Agrícola son las personas que poseen en común un determinado terreno, y por lo tanto, poner como eje del concepto el terreno, resultaba inadecuado y hasta lesivo a la dignidad de quienes conformaban la Comunidad Agrícola.

Como respuesta a lo anterior, la ley 19.233 modifica la definición de Comunidad superando las deficiencias anotadas y señalando que por Comunidad Agrícola se entiende 
" La agrupación de propietarios de un terreno rural común que lo ocupen, exploten o cultiven y que se organicen en conformidad con este texto legal". ${ }^{32}$

\section{2.- Determinación de la naturaleza jurídica de las CCAA.}

Con la vigencia del originario D.F.L. $n^{\circ} 5$, no existía certeza acerca de qué eran, desde el punto de vista de su naturaleza jurídica, las CCAA. En virtud de estar tratadas en una normativa especial y exhibir tantos elementos peculiares, no podían ser definidas a partir del concepto general de comunidad contemplado en el Código Civil. Tampoco la Ley las consagraba expresamente como personas jurídicas, es decir entes ficiticios capaces de ser titulares de derechos y obligaciones y de ser representadas judicial y extrajudicialmente.

A pesar de lo anterior, el art. 27 de la antigua norma, señalaba en su último inciso, que constituída la comunidad, actuaría en sus relaciones con terceros como una persona jurídica de derecho privado distinta de los comuneros que la componían. Al señalar que las CCAA podrían actuar COMO y no indicar que ERAN personas jurídicas, se suscitaban conflictos prácticos y jurídicos que entorpecían la actividad de las CCAA, siendo una de las materias mas delicadas, la relacionada con la opinión de ciertos sectores, que manifestaban que por no ser las CCAA personas jurídicas, no podían ser titulares de derechos de aprovechamiento de aguas. ${ }^{33}$

Asumiendo esta problemática, la ley 19.233 introduce un nuevo inciso, en el que señala que las CCAA que se constituyan, gozarán de personalidad jurídica desde la inscripción del predio en el Conservador de Bienes Raíces respectivo ${ }^{34}$. Por otra parte, la misma ley 19. 233, en un artículo transitorio, prescribe que las CCAA ya constituídas y organizadas en conformidad con el D.F.L. $n^{\circ} 19$ de 1963 o con el D.F.L. $n^{\circ} 5$ de 1968 , gozarán de personalidad jurídica a contar de la publicación de la ley 19.133, es decir, desde el 5 de Agosto de $1993^{35}$.

\section{3.- Definiciones básicas.}

2.3.1.- Comuneros:" Son los titulares de derechos sobre los terrenos comunes que figuren en la nómina que se confeccionen de acuerdo a este texto legal"16.

Esta norma clarifica taxativamente quienes serán las personas naturales que deberán ser consideradas comuneros. Existe la tendencia, en determinadas CCAA, a considerar comuneros a todos quienes han vivido u ocupado parte del terreno común durante un tiempo prolongado.

Desgraciadamente las normas que regulan el proceso de saneamiento de CCAA, permitieron que durante dichas gestiones, personas que legalmente debían ser consideradas como comuneros, no lo fueron por diversas razones: Desconocimiento de las normas respectivas o de las gestiones específicas, ausencias temporales durante el saneamiento, abusos de funcionarios o responsables del proceso, etc. Como producto de lo

${ }^{32}$ art. $1^{\circ}$ D.F.L. $n^{\circ}$ 5, modificado por ley 19.233

${ }^{33}$ Ver "Situación Jurídica de las Comunidades Agrícolas en Relación con sus Derechos de Aguas", Hernández R. y Rabuco A., JUNDEP, 1994.

${ }^{34}$ art. $1^{\circ}$ D.F.L. $n^{\circ} 5$, inciso $2^{\circ}$, modificado por ley 19.233.

${ }^{35}$ Ley 19.233 , art. $2^{\circ}$ transitorio.

${ }^{36}$ D.F.L. $n^{\circ} 5$, art. $1^{\circ}$ bis b, letra a). 
anterior, estas personas continúan considerándose como comuneros, con todas las dificultades que esta situación acarrea. La norma citada, zanja este problema, señalando cual es el instrumento público que certifica y acredita la calidad de comunero.

2.3.2.- Goce Singular:" Es una porción determinada de terreno propiedad de la comunidad que se asigna a un comunero y a su familia para su explotación o cultivo con carácter permanente y exclusivo ${ }^{137}$.

Este concepto, es uno de los que envuelve mayor importancia al interior de toda Comunidad Agrícola. Es en esta porción de terreno donde el comunero y su grupo familiar desarrollarán sus actividades vitales. Ahí vivirán, levantarán sus viviendas y trabajarán. EI uso de los goces singulares constituye el bien más importante que los comuneros poseen, y su calidad de permanente y exclusivo lo equiparan en la práctica, a la posesión de un terreno individual.

La ley ${ }^{38}$, indica, además, que un asignatario de un goce singular distribuído en la forma establecida en la ley, no podrá ser removido sin su expreso consentimiento. Esto significa que una vez adjudicado el goce singular, ni aún la primera autoridad de la Comunidad Agrícola, la Junta general de Comuneros, podrá despojar al comunero de su Goce Singular.

Resulta importante también mencionar que en la distribución de los goces singulares, el legislador ha dado una particular importancia al derecho consuetudinario de la Comunidad. La ley indica que en la distribución de los goces individuales( debe entenderse singulares) deberá ajustarse en lo posible, a la proporción de las cuotas o derechos, respetando las costumbres propias de las comunidad agrícola ${ }^{39}$.

En relación a este concepto, resulta adecuado también referirse a la modificación introducida por la ley 19.233 al art. $25^{\circ}$ del D.F.L. $n^{\circ} 5$. Mencionamos anteriormente que la ley 18.353 de 1984 , dentro de una política general de debilitamiento de las organizaciones campesinas, permitió a los comuneros inscribir a título individual los terrrenos que tenían asignados como goces singulares. Al ser estas tierras generalmente las más ricas del terreno comunitario, la Comunidad Agrícola perdía de esta forma sus terrenos más valiosos, sumándose además que muchas veces en el proceso de regularización del goce singular, junto con inscribirse el terreno, se inscribían a nombre del comunero, los derechos de aprovechamiento de aguas, derechos que en principio debían pertenecer a la comunidad agrícola y no a un comunero en particular ${ }^{40}$.

La ley modifica substancialmente el mencionado art. 25 , estableciendo hoy que " a las Comunidades Agrícolas constituídas y organizadas por esta ley, cuya solicitud hubiere sido aceptada por el Ministerio de Bienes Nacionales en conformidad a lo establecido en el

${ }^{37}$ D.F.L. $n^{\circ} 5$, art. $1^{\circ}$ bis b, letra b).

${ }^{38}$ D.F.L. $n^{\circ} 5$, art. $39^{\circ}$, inc. $6^{\circ}$.

${ }^{39}$ D.F.L. $n^{\circ} 5$, art. $19^{\circ}$.

${ }^{40}$ Ver "Situación Jurídica de la Comunidades Agrícolas en relación con sus Derechos de Aprovechamiento de Aguas", R. Hernández y A. Rabuco, JUNDEP, La Serena, 1994. 
art.3, no les serán aplicables las disposiciones contenidas en el decreto ley 2.695 , ni ninguna otra norma de saneamiento dirigida a la constitución del dominio" ${ }^{41}$.

La actual redacción, establece de una manera clara e inequívoca que nadie, ni aún un comunero (la ley no distingue al respecto) podrá intentar obtener la regularización e inscripción a nombre propio de un terreno ubicado al interior de una Comunidad Agrícola. En la forma que quedó redactada la modificación, tampoco se permite a los comuneros que obtuvieron la inscripción individual, devolver el terreno a la comunidad, para así obtener una restitución de su porcentaje de participación en la comunidad, que se vio disminuido por la aplicación del anterior art. $25^{\circ}$.

En razón de lo anterior, podemos afirmar que en la práctica existen dos tipos de goce singular:

a) Los goces singulares asignados por la Junta general de Comuneros, que no tienen un título ni inscripción separada del terreno comunitario; y.

b) Aquellos producto del proceso de inscripción individual de goces singulares, realizado en virtud de la modificación introducida por la ley 18.353 , que exhiben un título y una inscripción independientes del título e inscripción de la comunidad agrícola.

2.3.3.- Lluvia:" es una porción determinada de propiedad de la comunidad que se asigna a un comunero y a su familia por un tiempo determinado" ${ }^{42}$.

Este tipo de terreno de la comunidad agrícola, de acuerdo a la redacción legal, se distingue del goce singular, en que la lluvia no es asignada con un carácter de permanente, y al no estar consagrada expresamente la inamovilidad del titular, puede éste ser removido si así lo decide la Junta general de Comuneros.

Normalmente estos terrenos serán los lugares donde los comuneros realizarán sus siembras durante el tiempo que la tierra lo permita, y una vez generado el agotamiento productivo de la lluvia, el comunero procederá a solicitar a la comunidad un nuevo terreno en calidad de lluvia.

2.3.4.- Terreno común:" Es aquella parte de la propiedad de la comunidad sobre la cual no se ha constituído ningún goce singular o lluvia" 43

En estas tierras normalmente se desarrollará una de las actividades económicamente mas importantes al interior de las CCAA, el pastoreo del ganado caprino. La comunidad deberá regular la forma en que estos campos serán utilizados, arbitrando las medidas tendientes a lograr el mejor aprovechamiento posible para todos los miembros de la comunidad.

No debe confundirse terrenos comunes, que están claramente definidos por la norma legal citada, con terrenos comunitarios, que son aquellos sobre los cuales se extiende todo el dominio de la Comunidad Agrícola, independiente de que en ellos se haya constituído un goce singular o una lluvia.

\footnotetext{
${ }^{41}$ D.F.L. $n^{\circ} 5$, art. $25^{\circ}$, inc. $1^{\circ}$.

${ }^{42}$ D.F.L. ${ }^{\circ} 5$, art. $1^{\circ}$ bis b, letra C).

${ }^{43}$ D.F.L. $n^{\circ} 5$, art. $1^{\circ}$ bis b, letra d).
} 


\section{3.- Derechos de los comuneros.}

Todo comunero, por el hecho de ser tal, es dueño y ejerce un derecho de dominio, sobre un derecho o cuota en el predio común. La propiedad del comunero está constituida entonces, por un bien inmaterial, consistente en la parte alicuota en la propiedad común, que le permite participar proporcionalmente en la propiedad de todos y cada uno de los bienes de la Comunidad Agrícola. Este derecho es la clave en la relación jurídica existente entre cada comunero y la comunidad agrícola, ya que como señala la ley ${ }^{44}$, le permite a cada comunero el acceso al uso y goce de los bienes de la comunidad, en especial, y sin que esto signifique que la enumeración sea taxativa, podrán ejercerlos sobre:

3a.- Los terrenos comunes, en la forma que lo determine la Junta general de Comuneros.

3b.- Los goces singulares que les asigne la Junta general de Comuneros de un modo exclusivo y permanente, $y$;

3c.- Los derechos de aprovechamiento de aguas que posea la comunidad por la competente inscripción, de las aguas lluvias que caen o se recogen en el predio común y de las que corresponden a vertientes que nacen, corren y mueren dentro del mismo predio.

De los tres derechos nombrados, cabe la pena resaltar, que el ejercicio efectivo de ellos, depende de una declaración de voluntad previa de la primera autoridad de la Comunidad Agrícola, la Junta General de Comuneros, que asigna o autoriza el ejercicio específico de dichos derechos.

Conjuntamente con los derechos anteriores, se pueden encontrar otras facultades, que expresa o tácitamente, se extraen de la lectura de la ley:

3d.- Todo comunero tiene derecho a participar en las Juntas generales de Comuneros, y así intervenir en la conformación de la voluntad de la Comunidad Agrícola en la discusión y resolución de los asuntos de mayor trascendencia de la comunidad.

3e.- Todo comunero tiene derecho a ser elegido miembro del Directorio, salvas las exepciones establecidas en el art. $17^{\circ}$.

3f.- Para los efectos del subsidio habitacional rural las personas que figuren en la nómina de comuneros, tendrán el derecho de acceder a dicho subsidio, siendo título suficiente, figurar en la lista que esté debidamente inscrita en el registro de propiedad del Conservador de Bienes Raíces respectivo. ${ }^{45}$

\section{4.- Organización y funcionamiento de las CCAA.}

La ley fija un marco orgánico mínimo de las CCAA, fijando la existencia de a los menos dos órganos imprescindibles en la organización de toda comunidad: la Junta General de Comuneros y el Directorio.

Lo anterior, se establece sin perjucio que por la vía estatutaria, cada Comunidad resuelva la existencia de otros organos comunitarios, como por ejemplo, Junta de Vigilancia, Comisiones Revisoras de Cuentas o Capataces.

\footnotetext{
${ }^{44}$ D.F.L. $n^{\circ} 5$, art. $1^{\circ}$ bis, letra C).

${ }^{45}$ D.F.L. $n^{\circ} 5$, art. $39^{\circ}$ inc. 7 .
} 


\section{1.- Junta general de Comuneros,-}

4.1.1..- Concepto: La Junta general de Comuneros es la primera autoridad de la Comunidad Agrícola y sus acuerdos obligan a todos los comuneros, siempre que hubiesen sido tomados en la forma establecida en el respectivo estatuto y no fueren contrarios a las leyes o reglamentos. ${ }^{46}$

La Junta general de Comuneros, es el espacio de resolución democrática por excelencia al interior de la Comunidad Agrícola, y por eso, los asuntos de mayor trascendencia para la Comunidad, el legislador los consagra dentro de la competencia privativa de este órgano.

En relación a esta estructura, se debe insistir en la autonomía que la modificación de la ley 19.233 le entrega. El antiguo art. $16^{\circ}$ indicaba que las Juntas generales, debían efectuarse siempre con la asistencia de un abogado del Servicio, quien tenía derecho a voz. La misma norma establecía la obligación del Directorio de notificar a la oficina respectiva, el día, lugar y hora de las reuniones ordinarias y extraordinarias. Cuando por cualquier circunstancia no comparecía el abogado designado, el Directorio debía presentar a la Oficina del Ministerio de Bienes Nacionales, para su conocimiento, el acta de la Junta, dentro del plazo de quince días hábiles, bajo sanción de nulidad de los acuerdos.

Hoy día, la Junta general de Comuneros posee una completa soberanía para decidir la suerte de la comunidad, pudiendo ser ordinarias o extraordinarias y tomando sus acuerdos, por regla general, por la mayoría absoluta de los comuneros comparecientes.

Resulta importante señalar lo delicado que esta autonomía de la Junta general encierra, cuando no todos los comuneros hacen uso del derecho de participar en ellas. La ley señala que las Juntas generales, ordinarias o extraordinarias, sesionan en primera citación con la mayoría absoluta de los comuneros y en segunda citación con quienes asistan. $^{47}$

Esto significa que, salvas las excepciones legales o estatutarias, todos los acuerdos de la Junta general de Comuneros, pueden ser tomados por aquellos que acudan a la Junta, sin importar el porcentaje que dicho número represente del total de la masa comunera.

\subsection{2.- Atribuciones.}

\subsubsection{1.- Elección del Directorio.}

4.1.2.2.- Aprobar los planes de cultivo o aprovechamiento del terreno común y reglamentar su utilización, como también establecer medidas de protección de los suelos, aguas y bosques,

4.1.2.3.- Aprobar la distribución de los goces singulares y de los de aprovechamiento de aguas, a propuesta del Directorio. De los primeros se confeccionará una nómina que se archivará en la oficina respectiva y, de los segundos, en la oficina de la Dirección de Aguas. No se afectarán los goces singulares originarios existentes antes de la regularización de la comunidad.

\footnotetext{
${ }^{46}$ D.F.L. $n^{\circ} 5$, art. $16^{\circ}$.

${ }^{47}$ D.F.L. $n^{\circ} 5$, art. $16^{\circ}$, inc. $6^{\circ}$.
} 
4.1.2.4.- Fijar las cuotas máximas de ganado con derecho a pastoreo en las tierras comunes.

4.1.2.5.- Establecer sanciones pecuniarias para los casos de infracción a los estatutos, a los acuerdos de la Junta o del Directorio.

4.1.2.6.- Fijar el presupuesto de gastos y pronunciarse sobre la cuenta de inversiones que debe presentar el Directorio.

4.1.2.7.- Fijar las cuotas en proporción a la asignación de goces singulares y al uso de bienes comunes, con que deberán concurrir los comuneros para el financiamiento de la comunidad. Directorio.

4.1.2.8.- Nombrar inspectores para el examen de las cuentas que deba rendir el

4.1.2.9.- Prestar su aprobación para gravar o enajenar los terrenos comunes en conformidad a lo que dispongan los estatutos, en virtud de lo que prescribe el inc. $2^{\circ}$ del art. 24 del D.F.L. $n^{\circ} 5$.

4.1.2.10.- En general, resolver cualquier otra situación relativa a la administración de la Comunidad Agrícola.

\subsection{3.- Situaciones especiales.}

Insistimos en el hecho, que para resolver todos los asuntos anteriores, basta el acuerdo de la mayoría de los comuneros asistentes a la Junta en segunda citación, existiendo sí, materia en las cuales las atribuciones de la Junta general, se ven exigidas por la necesidad de contar con la aprobación de un número o porción de comuneros, que representen un porcentaje mínimo de los derechos inscritos. Entre estas materias encontramos:

4.1.3.1.- para enajenar o gravar en todo o parte los terrenos comunes y los derechos de aprovechamiento de aguas de una Comunidad Agrícola, se requerirá del consentimiento de todos los comuneros. ${ }^{48}$ Esta norma consagra lo que una primera aproximación al tema de las enajenaciones y gravamenes, pareciera ser la regla general y absoluta. Sin embargo, como se verá a continuación, no siempre será necesario contar con el consentimiento de todos los comuneros para acordar decisiones de esta naturaleza.

4.1.3.2.- La primera excepción la encontramos en el art. $25^{\circ}$, que indica que una enajenación parcial, o el establecimiento de un gravamen total o parcial con el objeto de desarrollar en esos terrenos algún proyecto de un organismo de la Administración del Estado o municipal, deberá contar con el consentimiento del $50 \%$ de los comuneros asistentes a la Junta general. recordando que en segunda citación una Junta general puede sesionar con los comuneros que comparezcan, una decisión de esta naturaleza podrá ser tomada por un reducido porcentaje de comuneros, a pesar de la importancia del tema.

4.1.3.3. Otra excepción a la norma de la unanimidad, la establece la ley, ${ }^{49}$ al indicar que los estatutos pueden otorgar a la Junta general de Comuneros la facultad de enajenar parcialmente, o de gravar total o parcialmente los terrenos o derechos de aprovechamiento

\footnotetext{
${ }^{48}$ D.F.L. $n^{\circ} 5$, art. $24^{\circ}$,

${ }^{49}$ D.F.L. $n^{\circ} 5$, art. $24^{\circ}$, inc. $2^{\circ}$.
} 
de aguas comunes, siempre que dispongan que los acuerdos se adopten con el consentimiento de, a lo menos, dos tercios de los comuneros que representen no menos del $70 \%$ de los derechos inscritos.

4.1.3.4.- La ley tambien indica que la Junta General, por acuerdo de los dos tercios de los asistentes, que represente al menos, el $50 \%$ de los derechos inscritos, siempre podrá autorizar al Directorio a hipotecar el inmueble común, en garantía de préstamos otorgados por instituciones públicas o por instituciones bancarias o financieras.

4.1.3.5.- Para arrendar por un plazo máximo de diez años, los terrenos comunes y los derechos de aprovechamiento de aguas, con exclusión de los goces singulares, se requiere del acuerdo de los dos tercios de los comuneros asistentes a la Junta General, que representen no menos del $50 \%$ de los derechos inscritos. ${ }^{50}$

4.1.3.6.- La modificación de estatutos puede realizarse sólo por acuerdo de Junta general extraordinaria y con el voto favorable, a lo menos de los dos tercios de los comuneros asistentes que representen no menos del $50 \%$ de los derechos inscritos. ${ }^{51}$

4.1.3.7.- Para liquidar la Comunidad, se requiere el acuerdo de la Junta general extraordinaria, adoptado por al menos dos tercios de los comuneros que representen no menos del $70 \%$ de los derechos inscritos. ${ }^{52}$

4.1.3.8.- Se podrá dividir o segregar una parte de los terrenos comunes, para instalar establecimientos económicos que tengan una vida independiente, o cuando así lo requiera el interés general, o para caucionar obligaciones relacionadas con proyectos de inversión propuestos por el Directorio. Bastará para ello el acuerdo de la Junta general extraordinaria, tomada por los dos tercios de los comuneros, que represente a lo menos, el $70 \%$ de los derechos inscritos. ${ }^{53}$

4.1.3.9.- La Junta General de Comuneros, puede autorizar la segregación o división parcial de sus terrenos comunes para establecer, en la parte segregada, propiedades individuales a favor de los que figuren en la nómina de comuneros, siempre que el acuerdo sea tomado en una Junta General Extraordinaria, Ilamada especialmente al efecto, por la mayoría absoluta de los asistentes, que representen no menos del $50 \%$ de los derechos inscritos. ${ }^{54}$

4.1.3.10.- Se debe señalar como respuesta a quienes ven en el sistema de Comunidades Agrícolas, una traba a la libre circulación de los inmuebles agrícolas, debido a los altos quorums exigidos legalmente para la validez de acuerdos como los anteriormente reseñados, que el artículo 42 bis del actual D.F.L. $n^{\circ} 5$, sanciona a los comuneros que no cancelan las cuotas acordadas para el financiamiento de la Comunidad, con la exclusión del porcentaje que representa su derecho en la propiedad comunitaria, para el cálculo de los quorums legales.

\footnotetext{
${ }^{50}$ D.F.L. N ${ }^{\circ} 5$, art. $24^{\circ}$ inc. $3^{\circ}$.

${ }^{51}$ D.F.L. $n^{\circ} 5$, art. $26^{\circ}$.

${ }^{52}$ D.F.L. $n^{\circ} 5$, art. $43^{\circ}$, inc. $3^{\circ}$.

${ }^{53}$ D.F.L. $n^{\circ} 5$, art. $49^{\circ}$, incs. $1^{\circ}, 2^{\circ}$ y $3^{\circ}$.

${ }^{54}$ D.F.L. $n^{\circ} 5$, art. $49^{\circ}$, inc. $4^{\circ}$ y siguientes.
} 
En otras palabras, para reunir la cantidad de votos necesarios para acordar, por ejemplo una segregación o una enajenación de terrenos comunitarios, no se exige la concurrencia efectiva del porcentaje exigido por la ley, sino que este porcentaje se extrae sobre el total de comuneros que se encuentran al día en sus cuotas.

\section{2.- Directorio.}

4.2.1.- Concepto.- El Directorio es el órgano ejecutivo y administrativo colegiado de la Comunidad Agrícola, constituido por comuneros elegidos por la Junta General y que funciona de una manera permanente.

" El Directorio se compondrá de no menos de cinco ni más de once miembros. Podrán designarse suplentes. los directores no podrán durar más de tres años en sus cargos, sin perjuicio de continuar en sus cargos mientras no se les designe un reemplazante". ${ }^{55}$

4.2.2.- Miembros y requisitos. Sólo podrán ser directores los comuneros mayores de edad. No podrán serlo aquellos que hubiesen sido condenados por delito que merezca pena aflictiva, o que hubiesen sido removidos de sus cargos en conformidad a lo dispuesto en el art. $18^{\circ} .{ }^{56}$

El Directorio designará de entre sus miembros, un presidente, un secretario y un tesorero. Sólo podrán elegirse para estos cargos a personas que sepan leer y escribir. EI Presidente tendrá la representación judicial y extrajudicial de la Comunidad Agrícola, en los términos señalados en el art. $8^{\circ} \mathrm{del} \mathrm{C}$. de procedimiento Civil. ${ }^{57}$

\subsection{3.- Atribuciones.-}

La ley en su artículo 20, señala una serie de atribuciones, que deben estar ratificadas por el estatuto respectivo de la Comunidad, ya que la redacción de la norma "Entre las atribuciones del Directorio deberán figurar las siguientes ...", sólo permite sacar esta conclusión.

Dentro de las facultades del Directorio, cabe destacar el art. $22^{\circ}$ del actual D.F.L. $n^{\circ} 5$, que restaura al Directorio, la facultad de buscar la conciliación en los conflictos que se susciten al interior de la Comunidad, atribución que le había sido retirada por la modificación de la ley 18.353. Entre la reforma citada de 1984 y la dictación de la ley 19.233, los conflictos internos de la Comunidad, solo podían ser resueltos por el Juzgado de letras respectivo, con todas las dificultades y gastos que eso implicaba.

Con la actual redacción, se reestablece un procedimiento alternativo de resolución de conflictos y paradójicamente, siendo una norma que responde al sustrato del derecho consuetudinario de las CCAA, se ubica dentro de una tendencia importante del derecho contemporáneo, cual es la de buscar espacios de solución de conflictos jurídicos, fuera del ámbito de las esferas judiciales. ${ }^{58}$

${ }^{55}$ D.F.L. $n^{\circ} 5$, art. $17^{\circ}$, inc. $1^{\circ}$.

${ }^{56}$ D.F.L. $n^{\circ} 5$, art. $17^{\circ}$,inc. $2^{\circ}$.

${ }^{57}$ D.F.L. $n^{\circ} 5$, art. 21 , incs. $1^{\circ}, 2^{\circ}$ y $3^{\circ}$.

${ }^{58} \mathrm{Ver}$ "Resolución Alternativa de Conflictos Jurídicos en Comunidades Agrícolas". Fda. Melis, JUNDEP-CPU, 1995. 
5.- Transferencia, transmisión de derechos, liquidación de las comunidades que sobre ellas se forman y prohibiciones.

Como todo bien susceptible de ser apropiado, el derecho o cuota que el comunero tiene sobre la Comunidad Agrícola, es susceptible de ser transmitido a los herederos del comunero, y puede ser también objeto de actos o negocios jurídicos, que implican el traspaso de un patrimonio a otro y su circulación económica.

Para la primera de estas situaciones, la ley establece un sistema especial el que regula la forma en que se determina la persona que heredará al comunero fallecido en la titularidad del derecho o cuota, fijando un estado de indivisión. Para la segunda, es decir el traspaso por acto entre vivos, la ley fija un sistema de formalización de contrato, que constituye una excepción a las reglas generales de contratos sobre bienes raíces.

\section{1.- Transmisión o traspaso por causa de muerte.}

\subsection{1.- Establecimiento de la indivisión.}

Resulta útil recordar que el Legislador no favorece el estado de indivisión. Se ha dicho que genera permanentemente problemas entre los comuneros en el aprovechamiento de la cosa común; obstaculiza la libre circulación de los bienes comunes e inhibe las posibilidades de inversión y mejoras. Ratificación de lo anterior en nuestra legislación, es la norma que consagra el derecho de todo comunero, de pedir la división de la cosa común. ${ }^{59}$

En materia de Comunidades Agrícolas, se establece una excepción a esta norma de carácter general, ya que el D.F.L. $n^{\circ} 5$ dispone que fallecido el comunero, los derechos en la Comunidad Agrícola, pertenecientes en todo o parte a la sociedad conyugal y el goce individual respectivo, deberán mantenerse indivisos mientras viva el otro cónyuge, a menos que sea él quien pida la liquidación de la comunidad formada al fallecimiento. Mientras subsista este régimen de indivisión, el cónyuge sobreviviente tendrá el carácter de administrador proindiviso de los referidos derechos y goces. ${ }^{60}$

Lo que encontramos aquí, entonces, es una consagración de una comunidad hereditaria, constituida por un derecho en una Comunidad Agrícola, que se mantiene en la indivisión, estableciéndose una excepción a los principios generales del derecho civil. En esta materia, el único que no está obligado a continuar en la indivisión, es el cónyuge sobreviviente, pero el resto de los herederos, salvas las situaciones de excepción, deberán mantenerse en la indivisión. En esta situación, claro está, no existe la posibilidad de ejercer la acción consagrada en el ya citado artículo 1.317 del Código Civil.

\subsection{2.-Establecimiento de una jerarquía hereditaria.}

En la liquidación de la sociedad conyugal y en la partición de bienes dejados por uno de los cónyuges, el cónyuge sobreviviente que tuviere parte en los derechos existentes en la Comunidad Agrícola, tendrá la preferencia para adjudicárselos, a justa tasación. A falta de cónyuge o de interés por parte de éste, tendrá preferencia el hijo legítimo, natural

${ }^{59}$ Código Civil, art. 1.317.

${ }^{60}$ D.F.L. $n^{\circ} 5$, art. $37^{\circ}$. 
o adoptado mayor de edad que residiere en el inmueble y trabajare en él. Entre varios con igual preferencia, ésta se hará valer por orden de edad, empezando por el mayor. ${ }^{61}$

En la perspectiva de evitar la disgregación de la propiedad sobre los derechos o cuotas en la Comunidad Agrícola, el legislador ha introducido una norma absolutamente diversa de la que regula el derecho sucesorio general. A juicio de algunos, se establece en esta norma, una morigeración al principio de igualdad ante la ley que la Constitución Política del Estado garantiza a todas las personas en su art. $19^{\circ}$, pero esta crítica, se rebate señalando que esta adjudicación individual, se realiza estableciendo una contraprestación, consistente en el pago de una indemnización establecida a justa tasación.

\subsection{3.- Organo competente.}

En los casos citados en los números inmediatamente anteriores, la División de Constitución de la Propiedad Raiz tendrá facultades para actuar como árbitro de derecho y como arbitrador en cuanto al procedimiento, a solicitud del o los interesados en los derechos existentes sobre la Comunidad Agrícola, sin que sea necesario la tramitación de la o las correspondientes posesiones efectivas. ${ }^{62}$

\section{2.- Transferencia o traspaso por acto entre vivos.}

La transferencia voluntaria de los derechos que se tengan en una Comunidad Agrícola podrá hacerse incluso por instrumento privado autorizado por el Jefe de la Oficina Provincial de Bienes Nacionales respectiva. El contrato se anotará en un registro especial que llevará para estos efectos, la Oficina de Bienes nacionales que corresponda. La oficina otorgará gratuitamente copia autorizada de estos actos, la que se anotará al margen de la nómina de comuneros señalada en el art. 27 del D.F.L. $n^{\circ} 5$. Esta anotación constituye la tradición de estos derechos. ${ }^{63}$

Ya señalábamos anteriormente, que los actos que impliquen el traspaso o constitución de un derecho real sobre un bien inmueble, por regla general, deben realizarse a través de una escritura pública. Toda venta de derecho real sobre un bien raiz, para existir jurídicamente y tener validez, debe ser celebrada a través de esta forma específica.

El art. $39^{\circ}$ del D.F.L. $n^{\circ} 5$ establece una forma más expedita, y desde el punto de vista del trámite, es mucho más barata la celebración de la compraventa, ya que puede consistir en un simple instrumento privado autorizado por el Jefe de la Oficina Provincial de Bienes Nacionales, y además establece una distinta modalidad de traspaso.

Para transferir el dominio de una propiedad raiz, se hace necesario que el título (la escritura pública), se inscriba en el registro de Propiedad del Conservador de Bienes Raíces respectivo. En materia de derechos sobre CCAA, la copia autorizada del instrumento, se anota al margen de la nómina de comuneros, sin necesidad de cumplir con el trámite de inscripción señalado para la adquisición del dominio sobre bienes raíces de carácter general.

\footnotetext{
${ }^{61}$ D.F.L. $n^{\circ} 5$, art. $38^{\circ}$, inc. $1^{\circ}$.

${ }^{62}$ D.F.L. $n^{\circ} 5$, art. $38^{\circ}$ inc. $2^{\circ}$.

${ }^{63}$ D.F.L. $n^{\circ} 5$, art, $39^{\circ}$, inc. $1^{\circ}$.
} 


\section{3.- Prohibiciones y sanciones.}

5.3.1.- Los derechos de los comuneros serán indivisibles. En consecuencia no podrá transferirse ni transmitirse el goce singular separado del derecho o cuota de la comunidad. ${ }^{64}$

Esta norma establece la imposibilidad que tiene todo comunero de realizar actos que impliquen traspasar su goce singular a un tercero, manteniendo su calidad de comunero o viceversa. ${ }^{65}$

5.3.2.- Durante el plazo de dos años, contado desde la constitución de la Comunidad, los comuneros y sus sucesores en el dominio no podrán enajenar voluntariamente sus derechos en la Comunidad Agrícola sino en beneficio de otro comunero o de la misma Comunidad Agrícola. ${ }^{66}$

Transcurrido el plazo anterior, sólo podrán transferirlos a una persona natural, sea o no comunero o a la propia Comunidad Agrícola. ${ }^{67}$

5.3.3.- Los derechos que podrán adquirir los comuneros sumados a los de que sean dueños, o los terceros, no podrán exceder del $3 \%$ de los derechos inscritos. ${ }^{68}$

Antes de la modificación de la ley 19.233, el máximo de participación en la propiedad comunitaria que podía exhibir un comunero, era de un $10 \%$. Dicho porcentaje aparecía como excesivo y encerraba el riesgo que pocos comuneros, a saber 5 , sin importar el número total de comuneros, podía influir de una manera decisiva en la suerte y vida de la Comunidad.

5.3.4.- Si un comunero dejare de pagar las cuotas a que se refiere el art. 18 letra g) del D.F.L. $n^{\circ} 5$, por un plazo superior a 90 días, su porcentaje de participación en la propiedad de la Comunidad no será considerado para los efectos de la aprobación de aquellas medidas que requieren, de acuerdo con la ley, la asistencia o voto favorable de un número mínimo de comuneros. Si la deuda acumulada por este concepto, iguala o supera el valor del derecho o cuota del comunero en la respectiva comunidad, ésta podrá pedir al Juez de letras que corrresponda, la adjudicación de sus derechos o cuota en compensación de lo adeudado. ${ }^{69}$

Sólo podrán adquirir estos derechos los hijos de comunero que figuren en la nómina respectiva. La adjudicación de estos derechos se hará en la forma establecida en los estatutos. Este procedimiento se seguirá siempre que la Comunidad Agrícola adquiera cuotas o derechos a cualquier título. ${ }^{70}$

${ }^{64}$ D.F.L. $n^{\circ} 5$, art. $39^{\circ}$, inc. $5^{\circ}$.

${ }^{65}$ Ver "Facultad de Disposición de Los Goces Singulares en las Comunidades Agrícolas", R. Hernández y A. Rabuco, JUNDEP 1995.

${ }^{66}$ D.F.L. $n^{\circ} 5$, art. $42^{\circ}$, inc. $1^{\circ}$.

${ }^{67}$ D.F.L. ${ }^{\circ} 5$, art. $42^{\circ}$, inc. $2^{\circ}$.

${ }^{68}$ D.F.L. $n^{\circ} 5$, art. $42^{\circ}$, inc. $3^{\circ}$.

${ }^{69}$ D.F.L. $n^{\circ} 5$, art. 42 bis inc. $1^{\circ}$.

${ }^{70}$ D.F.L. $n^{\circ} 5$, art. 42 bis inc. $2^{\circ}$. 
Si ningún hijo pudiese o quisiese adquirir estos derechos, podrán distribuirse a prorrata entre todos los comuneros. ${ }^{71}$

Esta norma, intenta establecer un mecanismo que por un lado, imponga una sanción a aquel comunero que no cumple con una obligación fundamental para con la Comunidad, y por otro, genera una alternativa de ingreso a la nómina de comuneros por parte de hijos de comunero, que de otra manera difícilmente podrían lograrlo, ya que como señalábamos, la titularidad en un derecho en Comunidades Agrícolas, no puede dividirse y debe transmitirse de manera definitiva, a sólo uno de los herederos del causante.

${ }^{71}$ D.F.L. $n^{\circ} 5$, art. 42 bis, inc. $3^{\circ}$. 
